\title{
The impact of working unit and being diagnosed with COVID-19 on secondary traumatic stress level in midwives: A cross-sectional and comparative study
}

\author{
Ayşe Nur Yılmaz ${ }^{1}$, Sümeyye Altıparmak ${ }^{2}$, Yeşim Aksoy Derya ${ }^{2}$ \\ ${ }^{1}$ Department of Midwifery, Faculty of Health Sciences, Firat University, Elazığ, Turkey \\ ${ }^{2}$ Department of Midwifery, Faculty of Health Sciences, Inonu University, Malatya, Turkey
}

Received: 2021-04-01. Accepted: 2021-06-18

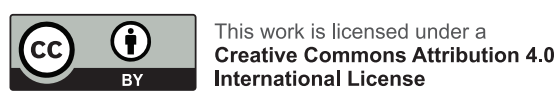

J Clin Med Kaz 2021; 18(4):46-51

Corresponding author:

Yeșim Aksoy Derya.

E-mail: yesim.aksoy@inonu.edu.tr;

ORCID: 0000-0002-3140-2286

\section{Abstract}

Aim: This research aims to determine the impact of the unit they work at and being diagnosed with Covid-19 on the secondary traumatic stress level in midwives.

Material and methods: Sample of the cross-sectional and comparative research consists of 170 midwives working in a province located in the east of Turkey. The data was collected with Personal Information Form and Secondary Traumatic Stress Scale (STSS). Descriptive statistics, t-test in independent groups and One-way Anova Analysis were used for data analysis.

Results: It was determined that $27.1 \%$ of the midwives work at Covid service, $28.8 \%$ work at community health/family health centers and $44.1 \%$ work at other services. It was determined that the rate of midwives who were diagnosed with Covid-19 during the pandemic was $69.4 \%$, the rate of midwives whose close colleagues were diagnosed with Covid-19 was 90.0\%. It was found that average scores that midwives get from STSS total and all subdimensions varied statistically significantly between the units they work at $(p<0.05)$ and this variance was caused by midwives working at Covid service and other services. It was determined that average score obtained from STSS total, "avoidance" and "stimulation" subdimensions was statistically significantly lower in midwives who were diagnosed with Covid-19 ( $p<0.05)$. In addition, it was determined that average score obtained from STSS total, "emotional violation" and "stimulation" subdimensions was statistically significantly higher in midwives whose close colleagues were diagnosed with Covid-19 $(p<0.05)$.

Conclusion: It was determined that midwives working at Covid-19 services experience higher secondary traumatic stress than those working at other services. In addition, while secondary traumatic stress level is higher in midwives whose close colleagues were diagnosed with Covid-19, it was determined that secondary traumatic stress level is lower in midwives who are diagnosed with Covid-19 than those who are not diagnosed.

Key words: Covid-19, Covid-19 diagnosis, working unit, midwife, secondary traumatic stress

\section{Introduction}

Breaking out in China, Covid-19 pandemic has spread to other countries quickly and become a big health issue. This pandemic is a global health crisis with big and devastating outcomes for individuals and societies. Furthermore, it is a global source of traumatic stress which might affect people directly or indirectly [1]. Both previous researches and recent findings indicate that contagious diseases and pandemics might be quite traumatic experiences and cause posttraumatic stress disorder (PTSD) and chronic psychological disorders for some people [1]. In addition, interruption of the daily life with quick spread of the Covid-19 pandemic and efforts to restrict the disease as a result of this (for example, travel restrictions, closing schools and workplaces and lockdown, etc.) has created numerous difficulties and stress such as job loss [2]. 
Negative impacts of traumatic life events can be observed on people directly experiencing such events as well as those who are in close communication with them. Frequently getting in contact with trauma victims because of their profession, healthcare professionals might be affected indirectly by traumatic live events they encounter $[3,4]$. Secondary traumatic stress is defined as the stress caused by helping or the urge to help a person who is traumatized or in pain [5]. Symptoms of secondary traumatic stress are similar to posttraumatic stress disorder. Symptoms such as excessive excitement, loss of concentration, insomnia, fatigue, nightmares, feeling of reliving an incident and avoidance behavior might occur as well. Sometimes, periods that are important for women such as pregnancy, birth and menopause might be traumatic. A key feature of midwifery is high level empathetic identification with women. Midwives develop close relationships with their clients and have the capacity to experience what they go through [5]. Those features of midwives might expose them to the risk of developing secondary traumatic stress [6]. In literature, it is reported that midwives' repeating experiences in relation to witnessing traumatic events might affect job satisfaction and keeping their jobs [5,7]. Midwives might start feeling vulnerable and worn due to the heavy emotional burden of their occupational obligations. In the event that midwives fail to cope with secondary stress effectively, adverse effects might occur in midwifery care [8]. In addition, midwives are right in the center of response to the pandemic. Women themselves and their families need midwifery support and care [9]. Stress caused by such traumas affects the workplace adversely, reduces affection during care, reduces care quality and might cause loss of motivation and exhaustion [8]. In addition, it is thought that midwives' diagnosis of Covid-19 as a result of their profession and their work in high-risk areas such as covid service during the pandemic process may be effective at the level of secondary traumatic stress [1]. Midwives who encounter traumatic events during the pandemic process and have to continue their professional practices without being affected by this situation are at risk for secondary traumatic stress [4]. In this process, they have concerns such as protecting their own health and making working conditions safe [10]. Based on such information, it is aimed in this research to determine the impact of working unit and being diagnosed with Covid-19 on secondary traumatic stress level in midwives.

\section{Material and methods}

This research, which is designed as cross-sectional and comparative, was conducted with midwives working at public hospitals and family health centers in the city center of a province located in east of Turkey between December 2020 and January 2021. 553 midwives are working at the said city center in total $(\mathrm{N}=553)$. When power analysis is conducted, sample size was determined as at least 127 with 0.05 level of significance, $80 \%$ power to represent the population and $80 \%$ confidence interval. Sample of the research was completed with 170 midwives who agreed to participate in the research.

Inclusion criteria for the research:

All midwives who:

- Have internet access,

- Have been doing this job for at least 1 year,

- Are currently on active duty,

- Have no diagnosed psychiatric medical problem are included in the research.

\section{Data collection instruments}

"Self-Description Form" and "Secondary Traumatic Stress Scale (STSS)" were used for data collection.

\section{Personal information form}

Drawn up by researchers in accordance with literature information, this form consists of 7 questions containing introductory features of midwives included in the research (age, marital status, education level, income status, which unit they work in, participant's or close colleagues' status of being diagnosed with Covid-19 during pandemic) $[5,11,12]$.

\section{Secondary Traumatic Stress Scale (STSS)}

Developed by Bride et al. (2004) with the purpose of measuring the posttraumatic stress symptoms that members of profession working with traumatized individuals develop secondarily and adapted to Turkish by Yildirim et al. (2018), Secondary Traumatic Stress Scale is a 5-point Likert scale consisting of 17 items and 3 subdimensions. Emotional violation (2, 3, 6, 10 and 13), Avoidance (1, 5, 7, 9, 12, 14 and 17) and Stimulation $(4,8,11,15$ and 16) are its subdimensions [13, 14]. Minimum score that can be obtained from the scale is 17 and maximum score is 85 . As the total score and subdimension scores obtained from the scale increase, exposure level increases. Cronbach's Alpha reliability coefficient of the scale is reported as $0.91[14]$. In this research, Cronbach's Alpha is found as 0.943 .

\section{Data collection}

Executives of the units where midwives work are contacted and all midwives were accessed by means of network mobile network system (WhatsApp network). Midwives who agreed to participate in the research confirmed informed consent form via Google Forms. Data collection forms were sent to participants via Google Forms and their answers are archived digitally. Collection of data took 5-10 minutes for each participant.

\section{Data Assessment}

The data is coded and assessed on computer environment using SPSS 22.0 software package. In statistical assessment; percentage distribution, arithmetic average, standard deviation, one-way anova test and t-test in independent groups are used. Results were assessed in 95\% confidence interval and significance was assessed on $\mathrm{p}<0.05$ level.

\section{Ethical Aspect of the Research}

For conducting the research, ethical approval was taken from Ministry of Health (2020-12-27T21_36_08) and Inonu University Health Sciences Scientific Research and Publication Ethical Committee (Decision No: 2021/1463). Aim of the study was explained to participants in detail and they were informed that participation is voluntary, their confidentiality and privacy will be reserved and they can quit the study whenever they want and informed consent was taken from participants for conducting and recording interviews. Helsinki Declaration principles were observed in the research.

\section{Limitations of the Research}

This research is limited to midwives who work in a province located in the east of Turkey and who volunteer to participate in the research. 


\section{Results}

Distribution of introductory features of midwives is given in Table 1. With an average age of $32.83 \pm 6.24$, it is stated that $59.4 \%$ of the midwives are married, $58.8 \%$ have bachelor's degree and $52.9 \%$ have income equal to their expense. It was determined that $27.1 \%$ of the midwives work at Covid service, $28.8 \%$ work at community health/family health centers $(\mathrm{CHC} /$ FHC) and $44.1 \%$ work at other services. While the rate of midwives who were diagnosed with Covid-19 during the pandemic was $69.4 \%$, the rate of having positive Covid-19 diagnosis among close colleagues was $90.0 \%$ (Table 1 ).

\section{Table 1 \\ Distribution of Introductory Features of} Midwives $(n=170)$

Descriptive Properties

\begin{tabular}{|c|c|c|}
\hline & Mean \pm SD & \\
\hline \multirow[t]{2}{*}{ Age (years) } & $32.83 \pm 6.24$ & \\
\hline & $\mathrm{n}$ & $\%$ \\
\hline \multicolumn{3}{|l|}{ Marital status } \\
\hline Married & 101 & 59.4 \\
\hline Single & 69 & 40.6 \\
\hline \multicolumn{3}{|l|}{ Educational level } \\
\hline High school & 25 & 14.7 \\
\hline Associate Degree & 36 & 21.2 \\
\hline Undergraduate & 100 & 58.8 \\
\hline Graduate & 9 & 5.3 \\
\hline \multicolumn{3}{|l|}{ Income Status } \\
\hline Income more than expenses & 21 & 12.4 \\
\hline Income and expense equivalent & 90 & 52.9 \\
\hline Revenue is less than expenses & 59 & 34.7 \\
\hline \multicolumn{3}{|l|}{ Working unit } \\
\hline $\begin{array}{l}\text { The primary healthcare institutions (PHC*, } \\
\text { FHC }^{* *} \text { ) }\end{array}$ & 49 & 28.8 \\
\hline $\begin{array}{l}\text { The secondary healthcare institution (Covid } \\
\text { Service) }\end{array}$ & 46 & 27.1 \\
\hline $\begin{array}{l}\text { The secondary healthcare institution (Other } \\
\text { Services) }\end{array}$ & 75 & 44.1 \\
\hline \multicolumn{3}{|l|}{ COVID-19 diagnosis during pandemic process } \\
\hline Yes & 118 & 69.4 \\
\hline No & 52 & 30.6 \\
\hline \multicolumn{3}{|l|}{ Covid-19 diagnosis among close colleagues } \\
\hline Yes & 153 & 90.0 \\
\hline No & 17 & 10.0 \\
\hline Total & 170 & 100.0 \\
\hline
\end{tabular}

Comparison of Average Scores that Midwives Obtain from Secondary Traumatic Stress Scale (STSS) Total and Subdimensions in terms of the Unit They Work At $(n=170)$

\begin{tabular}{|c|l|l|l|l|}
\hline STSS & $\begin{array}{l}\text { PHC/FHC } \\
(\mathrm{n}=49) \\
\text { Mean } \pm \text { SD }\end{array}$ & $\begin{array}{l}\text { Covid Service } \\
(\mathrm{n}=46) \\
\text { Mean } \pm \text { SD }\end{array}$ & $\begin{array}{l}\text { Other Services } \\
(\mathrm{n}=75) \\
\text { Mean } \pm \text { SD }\end{array}$ & $\begin{array}{l}\text { Test* } \mathrm{p} \\
\text { value** } \\
(\mathrm{sig})\end{array}$ \\
\hline Intrusion & $13.71 \pm 4.69 \mathrm{a}$ & $14.19 \pm 4.69 \mathrm{~b}$ & $12.02 \pm 4.38 \mathrm{c}$ & $\begin{array}{l}\mathrm{F}=3.845 \\
\mathrm{p}=0.023 \\
\mathrm{~b}>\mathrm{c}\end{array}$ \\
\hline Avoidance & $20.32 \pm 6.63 \mathrm{a}$ & $20.58 \pm 6.55 \mathrm{~b}$ & $18.00 \pm 5.94 \mathrm{c}$ & $\begin{array}{l}\mathrm{F}=3.182 \\
\mathrm{p}=0.044 \\
\mathrm{~b}>\mathrm{c}\end{array}$ \\
\hline Arousal & $15.85 \pm 5.75 \mathrm{a}$ & $16.00 \pm 5.48 \mathrm{~b}$ & $13.21 \pm 5.09 \mathrm{c}$ & $\begin{array}{l}\mathrm{F}=5.301 \\
\mathrm{p}=0.006 \\
\mathrm{a}>\mathrm{c}, \mathrm{b}>\mathrm{c}\end{array}$ \\
\hline Total & $49.89 \pm 16.06 \mathrm{a}$ & $50.78 \pm 15.47 \mathrm{~b}$ & $43.24 \pm 14.45 \mathrm{c}$ & $\begin{array}{l}\mathrm{F}=4.591 \\
\mathrm{p}=0.011 \\
\mathrm{~b}>\mathrm{c}\end{array}$ \\
\hline
\end{tabular}

* One-Way Anova Test

** $\mathrm{p}<0.05$

Comparison of average scores that midwives obtain from secondary traumatic stress scale (STSS) total and subdimensions in terms of the unit they work at is given in Table 2.

It was determined that the total average score that midwives working at $\mathrm{CHC} / \mathrm{FHC}$ get from STSS was $49.89 \pm 16.06$, average score they get from "emotional violation" subdimension was $13.71 \pm 4.69$, average score they get from "avoidance" subdimension was $20.32 \pm 6.63$ and average score they get from "Stimulation" subdimension was $15.85 \pm 5.75$. It was determined that the average scores that midwives working at Covid service were $50.78 \pm 15.47,14.19 \pm 4.69,20.58 \pm 6.55$ and $16.00 \pm 5.48$ respectively; average scores that midwives working at other services were $43.24 \pm 14.45,12.02 \pm 4.38,18.00 \pm 5.94$ and $13.21 \pm 5.09$ respectively (Table 2 ).

It was determined that average scores that midwives get from STSS total and all subdimensions varied statistically significantly in terms of the units they work at $(p<0.05)$ and this variance was caused by midwives working at Covid service and other services $(b>c)$. In addition, it was determined that STSS "Stimulation" subdimension average score was significantly lower in midwives working at other services than $\mathrm{CHC} / \mathrm{FHC}$ (a>c) (Table 2).

Comparison of average scores that midwives and close colleagues get from secondary traumatic stress scale (STSS) total and subdimensions according to being diagnosed with covid-19 is given in Table 3. (STSS) Total and Subdimensions according to Being Diagnosed with Covid-19 $(n=170)$

\begin{tabular}{|c|c|c|c|c|c|c|}
\hline \multirow[b]{2}{*}{ STSS } & \multicolumn{2}{|c|}{$\begin{array}{l}\text { Covid-19 diagnosis during pandemic } \\
\text { process }\end{array}$} & \multirow[t]{2}{*}{$\begin{array}{l}\text { Test* p value** } \\
\text { (sig) }\end{array}$} & \multicolumn{2}{|c|}{$\begin{array}{l}\text { Covid-19 diagnosis among close } \\
\text { colleagues }\end{array}$} & \multirow[t]{2}{*}{$\begin{array}{l}\text { Test* p value** } \\
\text { (sig) }\end{array}$} \\
\hline & Yes $(n=118)$ & No $(n=52)$ & & Yes $(n=153)$ & No $(n=17)$ & \\
\hline Intrusion Mean \pm SD & $12.82 \pm 4.45$ & $13.73 \pm 5.01$ & $\begin{array}{l}t=-1.178 \\
p=0.240\end{array}$ & $13.33 \pm 4.47$ & $10.94 \pm 5.60$ & $\begin{array}{l}t=2.041 \\
p=0.043\end{array}$ \\
\hline \begin{tabular}{|l|} 
Avoidance \\
Mean \pm SD
\end{tabular} & $18.56 \pm 6.19$ & $21.19 \pm 6.52$ & $\begin{array}{l}t=-2.504 \\
p=0.013\end{array}$ & $19.63 \pm 6.27$ & $17.00 \pm 7.13$ & $\begin{array}{l}\mathrm{t}=1.619 \\
\mathrm{p}=0.107\end{array}$ \\
\hline $\begin{array}{l}\text { Arousal } \\
\text { Mean } \pm \text { SD }\end{array}$ & $14.05 \pm 5.38$ & $16.26 \pm 5.60$ & $\begin{array}{l}\mathrm{t}=-2.244 \\
\mathrm{p}=0.016\end{array}$ & $15.09 \pm 5.40$ & $11.41 \pm 5.74$ & $\begin{array}{l}\mathrm{t}=2.652 \\
\mathrm{p}=0.009\end{array}$ \\
\hline \begin{tabular}{|l} 
Total \\
Mean $\pm S D$
\end{tabular} & $45.44 \pm 15.00$ & $51.19 \pm 16.08$ & $\mathrm{t}=-2.252$ & $48.07 \pm 15.03$ & $39.35 \pm 18.04$ & $\begin{array}{l}t=2.222 \\
p=0.028\end{array}$ \\
\hline
\end{tabular}

$*$ T test in independent groups

$* * \mathrm{p}<0.05$ 
STSS total average score of the midwives who were diagnosed with Covid-19 was $45.44 \pm 15.00$, their "emotional violation" subdimension average score was $12.82 \pm 4.45$, "avoidance" subdimension average score was $18.56 \pm 6.19$ and "stimulation" subdimension average score was $14.05 \pm 5.38$. As a result of the statistical evaluation; it was determined that average score obtained from Secondary Traumatic Stress Scale total, "avoidance" and "stimulation" subdimensions was statistically significantly lower in midwives who were diagnosed with Covid-19 ( $<<0.05$, Table 3$)$.

STSS total average score of the midwives whose close colleagues were diagnosed with Covid-19 was 48.07 \pm 15.03 , their "emotional violation" subdimension average score was $13.33 \pm 4.47$, "avoidance" subdimension average score was $19.63 \pm 6.27$ and "stimulation" subdimension average score was $15.09 \pm 5.40$. As a result of the statistical evaluation; it was determined that average score obtained from Secondary Traumatic Stress Scale total, "emotional violation" and "stimulation" subdimensions was statistically significantly higher in midwives whose close colleagues were diagnosed with Covid-19 $(\mathrm{p}<0.05$, Table 3$)$.

\section{Discussion}

During the Covid-19 pandemic, healthcare professionals face an increasing pressure of heavy workload [10]. In this process, healthcare professionals are fighting psychological problems as well as physical problems. Especially midwives who are right in the center of response to the pandemic are struggling to meet the midwifery support and care needs of women and their families at all times and under any circumstances [9]. In our research, while the rate of midwives who were diagnosed with Covid-19 during the pandemic was $69.4 \%$, the rate of midwives whose close colleagues were diagnosed with Covid-19 was $90.0 \%$ (Table 1). Turkey Izmir Medical Chamber reported that 155 doctors, 160 midwives/nurses/medical officers and 186 other healthcare workers were diagnosed with Covid-19 in Izmir province [15].

Secondary traumatic stress is the emotional state and stress reaction that an individual experiences as a result of witnessing a situation causing severe stress or tragic incident, having or being exposed to knowledge of such incident because of his/ her job [16]. In our research, it was determined that the total average score that midwives working at $\mathrm{CHC} / \mathrm{FHC}$ get from STSS was $49.89 \pm 16.06$, average score they get from "emotional violation" subdimension was $13.71 \pm 4.69$, average score they get from "avoidance" subdimension was $20.32 \pm 6.63$ and average score they get from "Stimulation" subdimension was $15.85 \pm 5.75$ (Table 2). It was determined that the average scores that midwives working at Covid service were $50.78 \pm 15.47$, $14.19 \pm 4.69,20.58 \pm 6.55$ and $16.00 \pm 5.48$ respectively; average scores that midwives working at other services were $43.24 \pm 14.45$, $12.02 \pm 4.38,18.00 \pm 5.94$ and $13.21 \pm 5.09$ respectively (Table 2).

In literature review, it is seen that STSS total average scores are at varying values such as $24.1 \pm 8.6,31.8 \pm 9.7,38.7 \pm 10.9$ in the studies conducted in Turkey and the world in pre-Covid period $[3,17,18]$. In this research, it is thought that the reason why STSS average scores are high because of the Covid-19 pandemic. The number of studies in which secondary traumatic stress level is evaluated is limited. In limited number of studies conducted with healthcare professionals, it was determined that secondary traumatic stress level varied between scores of $30.27 \pm 3.58$ and $36.41 \pm 12.79[19,20]$. In the study of Arpacioglu et al., it was determined that secondary traumatic stress scores of healthcare professionals who are fighting Covid-19 at the front line are significantly higher than other healthcare professionals or non-medical workers [21]. In studies conducted both before and after Covid, it was proven that women are affected more by secondary traumatic stress $[20,22,23]$. In the study of Kidak et al., it was determined that female healthcare professionals got higher scores than men in all measurements of secondary traumatic stress (Emotional violation, avoidance and stimulation) [18]. The fact that only midwives are discussed in this research and midwifery is a women's profession might be effective in increasing STSS total average score.

The fact that healthcare professionals experience fear of death in general, they treat people infected with the virus and they lose their relatives during the pandemic might cause stress and traumas [24]. In this research, it is observed that midwives exhibit avoidance attitudes (Table 2). It is thought that this might be caused by the fact that they are afraid of getting infected or their families and colleagues' getting infected with Covid-19. In the case report by Donmez et al., it was stated that the midwife who found out that she was infected experienced complex emotions such as sadness, shock, fear, anxiety and at the same time crying-laughing and she blamed herself for infecting her husband and questioned her profession [4].

In our research, it was found that average scores that midwives get from STSS total and all subdimensions varied statistically significantly in terms of the units they work at $(p<0.05)$ and this variance was caused by the midwives who work at Covid service and other services ( $b>c$ ) (Table 2). In their study, Favrod et al. reported that nurses working at newborn intensive care unit experienced more traumatic stress in their working environment compared to midwives working at hospital [3]. In their study, Kidak et al. determined that the fact that healthcare professionals working in a difficult field carry out their profession without loving increased the secondary traumatic stress [18]. In the study of Ozturk with healthcare professionals, it was determined that secondary traumatic stress total and subdimension average scores of healthcare professionals working at internal units were higher than healthcare professionals working at surgical units [25]. It is thought that midwives working at Covid service are affected by secondary traumas more is because that they spend more time with patient population applying to this unit, they internalize the situation and they are affected more by it. In addition, it was determined that STSS "stimulation" subdimension average score is significantly lower in midwives working at other services compared to $\mathrm{CHC} / \mathrm{FHC}(\mathrm{a}>\mathrm{c})$. Midwives working at hospital experience work related stress factors frequently compared to midwives working at $\mathrm{CHC} / \mathrm{FHC}$ and for that reason, they are vulnerable to development of mental health problems such as secondary traumatic stress, exhaustion, anxiety and depression [3]. In the study that Mangoulia et al. conducted with nurses, it was found that working with patients who do not show rapid improvement affected stress level of nurses negatively [26].

A key feature of midwifery is high level empathetic identification with women. This increases their risk of experiencing secondary traumatic stress [5]. In our research, it was determined that STSS total and "emotional violation" and "stimulation" subdimension average scores of the midwives whose close colleagues are diagnosed with Covid-19 are higher than midwives whose close colleagues are not diagnosed with Covid-19 (Table 3). It is thought that this is caused by the empathetic relationship between midwives and their close colleagues. In literature, it is reported that traumatic incidents that occur in a clinic environment might have long-term 
adverse effects on those who are affected, including healthcare professionals [27]. For that reason, it can be concluded that midwives are affected negatively by the Covid-19 related processes at the work environment and this causes secondary trauma in midwives.

However, it was determined that average score obtained from STSS total, "avoidance" and "stimulation" subdimensions are statistically significantly lower in midwives who are diagnosed with Covid-19 $(\mathrm{p}<0.05$, Table 3$)$. The fact that being diagnosed with Covid-19 is a factor reducing secondary traumatic stress level in midwives is an outstanding finding $(\mathrm{p}<0.05$, Table 3$)$. No study was found in literature assessing the secondary traumatic stress level in individuals who are diagnosed. However, education level and special trainings on trauma might affect increase of perceived social support, and also feeling of healing and relaxation might affect decrease of secondary traumatic stress symptoms [28]. For that reason, it can be concluded that feeling of healing and relaxation decreases secondary traumatic stress level in midwives who are diagnosed.

\section{Conclusion and recommendations}

In this study on the impact of the working unit and being diagnosed with Covid-19 on the secondary traumatic stress level in midwives, it was determined that midwives working at Covid-19 services experience higher levels of secondary traumatic stress than those working at other services. In addition, while it is seen that secondary traumatic stress level is higher in midwives whose close colleagues are diagnosed with Covid-19, it was determined that secondary traumatic stress level is lower in midwives who are diagnosed with Covid-19 compared to those who are not diagnosed. In these days when fighting against Covid-19 pandemic is getting bigger, midwives who are frequently getting in contact with trauma victims might be affected indirectly by the traumatic life events that they encounter. With the purpose of minimizing the indirect trauma reactions that midwives experience and avoiding problems such as emotional labor vested in the job and becoming insensitive, it is necessary that working conditions are improved, social support level is increased and methods of coping with stress should be deployed. Therefore, if their job satisfaction and motivation increase, midwives would make sure that more quality healthcare services are rendered.

Disclosures: There is no conflict of interest for all authors.

Acknowledgements: We would like to thank the midwives who participated and completed this questionnaire.

Funding: The financial support for this study was provided by the investigators themselves.

\section{References}

1. Boyraz G, Legros DN, Tigershtrom A. COVID-19 and traumatic stress: The role of perceived vulnerability, COVID-19-related worries, and social isolation. J Anxiety Disord. 2020;76:102307. doi:10.1016/j.janxdis.2020.102307

2. Brooks SK, Webster RK, Smith LE, Woodland L, Wessely S, Greenberg N, Rubin GJ. The psychological impact of quarantine and how to reduce it: rapid review of the evidence. Lancet. 2020;395(10227):912-920. doi:10.1016/S0140-6736(20)30460-8

3. Favrod C, Jan du Chêne L, Martin Soelch C, Garthus-Niegel S, Tolsa JF, Legault F, et al. Mental Health Symptoms and WorkRelated Stressors in Hospital Midwives and NICU Nurses: A Mixed Methods Study. Front Psychiatry. 2018;9:364. doi:10.3389/ fpsyt.2018.00364

4. Donmez A, Canbulut N, Karacam Z. Clinical features and experiences of a midwife with COVID-19: a case study. Journal of Education and Research in Nursing 2020;17(4):349-53.

5. Beck CT, LoGiudice J, Gable RK. A mixed-methods study of secondary traumatic stress in certified nurse-midwives: shaken belief in the birth process. J Midwifery Womens Health. 2015;60(1):16-23. doi:10.1111/jmwh.12221

6. Leinweber J, Rowe HJ. The costs of 'being with the woman': secondary traumatic stress in midwifery. Midwifery. 2010;26(1):76-87. doi:10.1016/j.midw.2008.04.003

7. Rice H, Warland J. Bearing witness: midwives experiences of witnessing traumatic birth. Midwifery. 2013;29(9):1056-1063. doi:10.1016/j.midw.2012.12.003

8. Bayri Bingol F, Demirgoz Bal M, Aygun M, Bilgic E. Secondary traumatic stress among midwifery students Perspect Psychiatr Care. 2020;10.1111/ppc.12674. doi:10.1111/ppc.12674

9. Bick D. COVID-19: 2020 is the International Year of the Midwife. Midwifery. 2020;85:102719. doi:10.1016/j.midw.2020.102719

10. Shoja E, Aghamohammadi V, Bazyar H, Moghaddam HR, Nasiri K, Dashti M, et al. Covid-19 effects on the workload of Iranian healthcare workers. BMC Public Health. 2020;20(1):1636. Published 2020 Nov 2. doi:10.1186/s12889-020-09743-W

11. Aksoy Derya Y, Altiparmak S, Akca E, Gokbulut, N, Yilmaz, AN. Pregnancy and birth planning during COVID-19: The effects of teleeducation offered to pregnant women on prenatal distress and pregnancy-related anxiety. Midwifery. 2021; 92: 102877.

12. Dogan Yuksekol O, Orhan I, Yilmaz AN. Midwifery and nursing students information on the Covid-19 pandemic and the precautions they take for protection. ACU Journal of Health Sciences 2021;12(2): 487-495 https://doi.org/10.31067/acusaglik.851937

13. Bride BE, Robinson MM, Yegidis B, Figley CR. Development and validation of the secondary traumatic stress scale. Research on Social Work Practice. 2004;14(1):27-35. doi:10.1177/1049731503254106

14. Yildirim G, Kidak LB, Yurdabakan I. Secondary traumatic stress scale: an adaptation study. Anatolian Journal of Psychiatry. 2018;19(1), 45-51.

15. Izmir Medical Chamber. Health Workers Diagnosed with Covid-19 in Izmir. Available from: http://www.izmirtabip.net/uncategorized/ izmirde-covid-19- tanili-saglik-calisanlari/

16. Gürkan A, Yalçıner N. Secondary traumatıc stress in health workers. GÜSBD 2017; 6(2):90-95.

17. Oe M, Ishida T, Favrod C, Martin-Soelch C, Horsch A. Burnout, Psychological Symptoms, and Secondary Traumatic Stress Among Midwives Working on Perinatal Wards: A Cross-Cultural Study Between Japan and Switzerland. Front Psychiatry. $2018 ; 9: 387$. Published 2018 Sep 4. doi:10.3389/fpsyt.2018.00387 
18. Kidak LB, Yildirim G, Yurdabakan I. Examination of factors affecting to secondary traumatic stress, cynicism and burnout in healthcare professionals. TJFMPC. 2019;13(2):196-202.

19. Secosan I, Virga D, Crainiceanu ZP, Bratu T. The Mediating Role of Insomnia and Exhaustion in the Relationship between Secondary Traumatic Stress and Mental Health Complaints among Frontline Medical Staff during the COVID-19 Pandemic. Behav Sci (Basel). 2020;10(11):164. Published 2020 Oct 26. doi:10.3390/bs10110164

20. Orrù G, Marzetti F, Conversano C, Vagheggini G, Miccoli M, Ciacchini R, et al. Secondary Traumatic Stress and Burnout in Healthcare Workers during COVID-19 Outbreak. Int J Environ Res Public Health. 2021;18(1):337. Published 2021 Jan 5. doi:10.3390/ ijerph18010337

21. Arpacioglu S, Gurler M, Cakiroglu S. Secondary Traumatization Outcomes and Associated Factors Among the Health Care Workers Exposed to the COVID-19 [published online ahead of print, 2020 Jul 8]. Int J Soc Psychiatry. $2020 ; 20764020940742$. doi:10.1177/0020764020940742

22. Baum N. Secondary Traumatization in Mental Health Professionals: A Systematic Review of Gender Findings. Trauma Violence Abuse. 2016;17(2):221-235. doi:10.1177/1524838015584357

23. Shevlin M, McBride O, Murphy J, Miller JG, Hartman TK, Levita L, et al. Anxiety, depression, traumatic stress and COVID-19related anxiety in the UK general population during the COVID-19 pandemic. BJPsych Open. 2020;6(6):e125. Published 2020 Oct 19. doi:10.1192/bjo.2020.109

24. Aykut S, Soner Aykut S. The importance of social work on the basis of post-traumatic stress disorder and the Covid-19 pandemic. Journal of Social Politics. 2020;1(1):56-66

25. Ozturk G. Determination of secondary traumatic stress level according to the unit of health personnel. Burdur Mehmet Akif Ersoy University Institute of Health Sciences, Department of Health and Biomedical Sciences (Interdisciplinary), Master Thesis, Burdur, 2019.

26. Mangoulia P, Koukia E, Alevizopoulos G, Fildissis G, Katostaras T. Prevalence of Secondary Traumatic Stress Among Psychiatric Nurses in Greece. Arch Psychiatr Nurs. 2015;29(5):333-338. doi:10.1016/j.apnu.2015.06.001

27. Kerkman T, Dijksman LM, Baas MAM, Evers R, van Pampus MG, Stramrood CAI. Traumatic Experiences and the Midwifery Profession: A Cross-Sectional Study Among Dutch Midwives. J Midwifery Womens Health. 2019;64(4):435-442. doi:10.1111/jmwh.12946

28. Kahil A, Palabıyıkoğlu NR. Secondary traumatic stress. Current Approaches in Psychiatry 2018;10(1):59-70 doi:10.18863/pgy.336495 